\title{
AVALIAÇÃO ECONÔMICA E DE EMISSÕES DE CO2 DA RECICLAGEM DE RESÍDUOS DE CONSTRUÇÃO E DEMOLIÇÃO CLASSE A: ESTUDO PARA GOIÂNIA - GO
}

\section{ECONOMIC AND CO2 EMISSIONS ASSESSMENT OF CONSTRCTUON AND DEMOLITION CLASS A WASTE: CASE STUDY FOR GOIÂNIA- GO}

Sara Duarte Sacho (UFG)

Lucas Rosse Caldas, M.Sc (UnB)

Simone Costa Pfeiffer, Dra. (UFG)

Rosa Maria Sposto, Dra. (UnB)

Palavras Chave

$\mathrm{RSCD}$; resíduos classe A; reciclagem; custos; $\mathrm{CO}_{2}$

\section{Key Words}

$C \& D$ waste; class $A$ waste; recycling; costs; $\mathrm{CO}_{2}$

\section{RESUMO}

O uso cada vez maior de resíduos sólidos da construção e demolição (RSCD), principalmente os resíduos Classe A, para a produção de agregados para pavimentação surgiu nos últimos anos como uma alternativa interessante para atingir os objetivos da sustentabilidade ambiental, porém o seu custo muitas vezes ainda é alto devido entre outros fatores, ao desenvolvimento tecnológico nacional existente para reciclagem, incluindo uso de energia. Diante disso, este trabalho se propõe a analisar a viabilidade econômica e ambiental destes resíduos. Além dos custos, foi feita uma quantificação das emissões de dióxido de carbono $\left(\mathrm{CO}_{2}\right)$ da reciclagem de resíduos Classe $\mathrm{A}$, considerando-se um estudo de caso no município de Goiânia - GO. Foram coletados dados em uma usina de reciclagem existente na região. A partir da análise econômi$\mathrm{ca}$, observou-se que o material reciclado apresentou valor de mercado superior ao do agregado convencional fornecido pelas principais empresas goianas. Em relação às emissões de $\mathrm{CO}_{2}$, observou-se que a usina de reciclagem gera um valor de $2,6 \mathrm{kgCO}_{2} / \mathrm{t}$, que ficou entre os valores encontrados na literatura. Concluiu-se que a reciclagem de resíduos classe $\mathrm{A}$ para a realidade goiana é viável do ponto de vista de emissões, no entanto não vantajosa do ponto de vista econômico.

\section{ABSTRACT}

The increasing use of solid waste from construction and demolition (C\&D), mainly Class A waste, for the production of aggregates for paving emerged in recent years as an attractive alternative to achieve the goals of environmental sustainability. However, costs are still high due among other factors to the existing national technological development for recycling, including energy use. Thus, this study aims to analyze the economic and environmental viability of this waste. In addition to costs assessment, a quantification of carbon dioxide $\left(\mathrm{CO}_{2}\right)$ from the recycling of Class $\mathrm{A}$ waste was made considering a case study in the city of Goiania - GO. Data were collected in an existing recycling plant in the region. From the economic analysis, it was found that the recycled material had a higher market value than the conventional aggregate supplied by major companies of Goiânia. Regarding $\mathrm{CO}_{2}$ emissions, it was observed that the recycling plant generates a value of $2.6 \mathrm{kgCO} 2 / \mathrm{t}$, which was among the values found in the literature. It was concluded that the recycling of Class A waste for reality of Goiânia is feasible in terms of $\mathrm{CO}_{2}$ emission, however it was not advantageous from an economic point of view. 


\section{INTRODUÇÃO}

A construção civil é reconhecida como um dos principais setores das atividades humanas, responsável pelo desenvolvimento econômico e social de qualquer país. No entanto, este desenvolvimento gera consequências negativas, como a exaustão dos recursos naturais, poluição do solo, água e atmosfera, modificação da paisagem natural e geração de grandes quantidades de resíduos.

No Brasil são geradas em média 0,6 toneladas de resíduos da construção e demolição (RSCD) por habitante todos os anos, o que representa o dobro da geração per capita de resíduos sólidos domiciliares, e 2/3 da massa de resíduos sólidos urbanos gerados nos municípios brasileiros (SINDUSCON, 2011). Esta grande quantidade de resíduos, quando mal gerenciada é responsável pela degradação da qualidade de vida urbana, sobrecarga dos serviços municipais de limpeza pública e possibilidade de trazer riscos à saúde pública.

Hendriks et al. (2004), Addis (2010) e Torgal et al. (2013) são alguns autores internacionais que abordaram o assunto relativo aos RSCD, e John (2000), Carneiro et al. (2001), Miranda et al. (2009) e Silva et al. (2015) autores nacionais.

No Brasil, já existem legislações e normas para os RSCDs, entre elas a Lei 12.305/2010, as Resoluções Conama $307 / 2002$, Conama 348/2004, Conama 431/2011, Conama 448/2012 e Conama 469/2015. A Lei 12.305/2010 define a Política Nacional dos Resíduos Sólidos, em que os RSCD também são discutidos. A Conama 307/2002 foi a primeira legislação específica voltada para os RSCD e as outras resoluções do Conama são modificações da primeira.

Entre as normas podem ser citadas as ABNT NBR 10004:2004, a ABNT NBR 15114:2004, a ABNT NBR 15115:2004 e a ABNT NBR 15116:2004. A primeira trata da classificação de tipos de resíduos, enquanto as outras são voltadas para a reciclagem e reaproveitamento de resíduos em obras de pavimentação, como agregados reciclados (resíduos classe A).

O Estado de Goiás foi um dos pioneiros a abordar o tema dos RSCD por meio da Política Estadual dos Resíduos Sólidos, com a publicação da Lei 14.248/2002.

De acordo com a Resolução Conama 307/2002, os RSCD são classificados em quatro classes: (A) - São os resíduos reutilizáveis ou recicláveis como agregados como resto de concreto, argamassa, cerâmica, solo; (B) - São os resíduos recicláveis para outras destinações, tais como: plásticos, papel/papelão, metais, vidros, madeiras, gesso; (C) - São os resíduos para os quais não foram desenvolvidas tecnologias ou aplicações economicamente viáveis que permitam a sua reciclagem/recuperação e (D) - São os resíduos perigosos oriundos do processo de construção, tais como: tintas, solventes, óleos, amianto e outros (BRASIL, 2002; BRASIL, 2004; BRASIL, 2011).

Apesar da existência de um arcabouço legal já consolidado, o que se observa na prática, é o não cumprimento das exigências, com formas de gerenciamento inadequadas dos RSCD, principalmente quando se trata da destinação final dada a estes resíduos, que em muitas vezes é realizada em locais inadequados.

De acordo com Ferreira (2010), atualmente podem ser encontradas três formas principais de destinação dos RSCD em Goiânia: Procedimentos de reciclagem e reutilização; Pontos de descarga clandestinas; e disposição no Aterro Sanitário Municipal. Nesse contexto, observa-se que em muitas obras é realizada a separação adequada destes resíduos em caçambas (CALDAS et al., 2015), no entanto, grande parte destes são enviados ao Aterro Sanitário Municipal, como verificado por Oliveira et al. (2013a), ou seja, em desacordo com o que é definido na Conama 448/2012, que determina que nesses casos os resíduos Classe A devem ser encaminhados para um aterro específico para RSCD. (BRASIL, 2012).

Neste sentido, a reciclagem dos resíduos Classe $A$ e a sua incorporação como agregados reciclados torna-se uma importante forma de destinação final destes resíduos, devendo ser incentivada pelos gestores municipais. Esta tem dois principais benefícios: diminuição do consumo de recursos naturais virgens (areia e brita) e diminuição das áreas destinadas à disposição final destes resíduos.

De acordo com Ângulo et al. (2003), o processo de reciclagem dos RSCD pode ser considerado de forma simplificada um beneficiamento mineral, que compreende um conjunto de quatro operações unitárias divididas em: triagem; britagem; peneiramento; e auxiliares.

Os agregados reciclados podem ser utilizados em diversos serviços de engenharia como: camadas drenantes; lastros para assentamento de tubos ou de guias; envelopamento de galerias; estabilização de solos expansíveis ou com baixa capacidade de suporte; regularização e cascalhamento de ruas de terra; e pavimentação. Eles também podem ser utilizados na produção de concreto e argamassa para uso em contrapisos; componentes para alvenaria e infra estrutura urbana como blocos e meios-fios (MOTTA, 2005).

Dentre as aplicações apresentadas anteriormente, o emprego dos agregados reciclados em camadas de base, sub-base ou reforço de subleito de pavimentação tem-se mostrado promissor com uma boa aceitação no mercado de materiais para obras rodoviárias, diante a disponibilidade do material e da existência de uma tecnologia acessível de reciclagem. Assim, várias cidades do Brasil e no 
exterior, já utilizam agregados reciclados na pavimentação visto que seus resultados são satisfatórios, por serem alternativas muito interessantes na substituição de materiais naturais, não renováveis, principalmente na pavimentação de vias de baixo volume de tráfego (LUZ; SAMPAIO, 2004).

É importante lembrar que a reciclagem dos RSCD, assim como qualquer atividade humana, também pode causar impactos ao meio ambiente. Fatores como o tipo de resíduo, a tecnologia empregada e a utilização proposta para o material reciclado, podem tornar o processo de reciclagem ainda mais impactante do que o próprio resíduo antes de ser reciclado. Por isso, a reciclagem apresenta riscos ambientais que precisam ser adequadamente gerenciados (JOHN, 2001).

Alguns estudos internacionais têm tido como objetivo a avaliação ambiental de concretos com agregados reciclados como o de Turk et al. (2015), Jiménez et al. (2015) e Serres et al. (2016). Todos concluíram a viabilidade ambiental da utilização de agregados reciclados, mas ressaltam a importância de avaliar as realidades específicas de cada caso, tais como tecnologia empregada, distâncias de transporte e viabilidade dos agregados naturais, entre outras.

Neste sentido, o processo de reciclagem dos RSCD, principalmente os resíduos Classe $A$, necessita ser bem planejado, que deve ser considerado além de questões técnico- econômicas, ambientais e sociais, apontado como tripé da sustentabilidade (SEIFFERT, 2011). O seguinte questionamento deve ser realizado: a reciclagem para os resíduos Classe $A$, de certa região, possui viabilidade técnica, econômica e ambiental?

A partir desta pergunta surgiu a motivação para a realização do presente trabalho, que tem como objetivo a avaliação econômica e ambiental dos resíduos Classe $A$ do município de Goiânia - GO em uma indústria de reciclagem.

Para a avaliação econômica foram comparados os custos de aquisição do agregado natural em relação ao agregado reciclado de uma empresa pesquisada. Para a avaliação ambiental foi escolhido como critério as emissões de dióxido de carbono $\left(\mathrm{CO}_{2}\right)$ geradas no processo de reciclagem em relação aquelas geradas na produção do agregado natural. Foi dada preferência pelas emissões de $\mathrm{CO}_{2}$ por este ser um dos aspectos ambientais mais relevantes dos últimos anos e de importância mundial, pois é um importante indicador do efeito estufa e aquecimento global (JOHN, 2010).

\section{METODOLOGIA}

A metodologia utilizada foi dividida em quatro etapas: (1) pesquisa bibliográfica, (2) Caracterização da empresa pesquisada; (3) Avaliação dos custos; (4) Avaliação das emissões de CO2. As etapas foram apresentadas a seguir.

\subsection{Pesquisa bibliográfica}

A pesquisa bibliográfica consistiu no estudo de literatura internacional e nacional, incluindo legislações e normas relacionadas à reciclagem de RSCD, com foco nos resíduos classe A, e alternativas para realizar a avaliação econômica e ambiental. As informações obtidas na pesquisa bibliográfica serviram de embasamento para as outras etapas da metodologia e o restante do presente trabalho.

\subsection{Caracterização da empresa pesquisada}

Nessa etapa foram realizadas visitas técnicas à usina da empresa selecionada durante três meses do ano de 2015; foram feitas entrevistas com os profissionais envolvidos e solicitados documentos com o objetivo de coletar dados sobre o processo de reciclagem utilizado, referentes aos:

- Custos de operação e manutenção dos equipamentos;

- Produtividade e quantidade de resíduo reciclado;

- Informações sobre a qualidade e desempenho do produto reciclado;

- Estudo sobre a tecnologia empregada;

- Levantamento e caracterização das máquinas utilizadas no processo;

- Consumo energético anual da usina;

- Principais fornecedores e clientes;

- Principais dificuldades encontradas no mercado goiano

Os dados foram coletados a partir de um questionário, elaborado pelos próprios autores e tabulados em planilha eletrônica (Microsoft Excel). Foi também realizado registro fotográfico das principais atividades desenvolvidas na usina.

\subsection{Avaliação econômica}

Para a avaliação econômica foi levantado o valor de venda da brita graduada simples (BGS), por este ser o produto gerado em maior quantidade e de maior interesse para a utilização na pavimentação. Para isto foram comparados três valores do material, considerando a representatividade na região goiana:

- Pesquisa dos valores de mercado da BGS nas três principais fornecedoras desse material em Goiânia.

- Valor encontrado no Custo Referencial de Materiais para atividades de terraplanagem, pavimentação e obras de arte especiais, elaborado pela Agência Goiana de Transportes e Obras (AGETOP, 2014).

- Valor comercial da BGS produzida pela empresa pesquisada.

Os valores obtidos foram apresentados em $\mathrm{R} \$$ (reais) por volume de GBS produzido, em $\mathrm{m}^{3}$. 


\subsection{Avaliação das emissões de $\mathrm{CO}_{2}$}

Para a avaliação ambiental foram levantadas as emissões de $\mathrm{CO}_{2}$ do processo de reciclagem e foram comparadas com emissões de agregados graúdos (brita) presentes na literatura, obtidos na etapa da pesquisa bibliográfica.

Para quantificar as emissões de $\mathrm{CO}_{2}$ foi necessário converter a energia elétrica consumida no processo juntamente com os combustíveis utilizados. O consumo de energia elétrica foi obtido a partir das potências das máquinas utilizadas no processo de reciclagem e os combustíveis pelo consumo (em L/h) da pá carregadeira. Não foi considerado o transporte dos resíduos do local de origem até a usina, somente as emissões relativas ao sistema produtivo, visto que os resíduos que chegam a usina são provenientes de diversas localidades.

Na Figura 1 é apresentado o fluxograma do processo.

Figura 01 - Processo de reciclagem e emissões de $\mathrm{CO}_{2}$

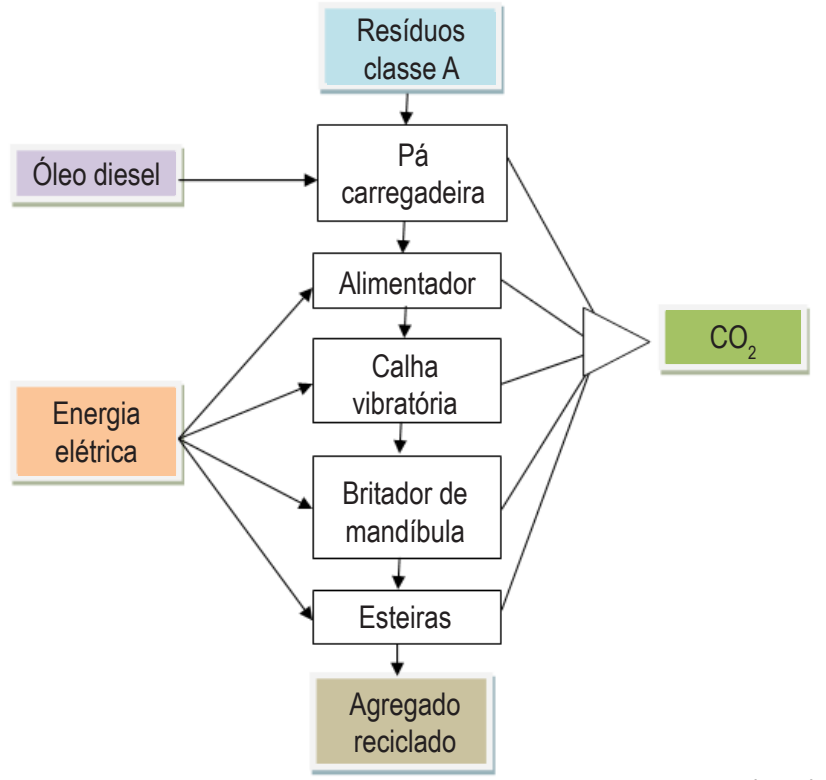

Fonte: Dos autores (2015)

Para a conversão da energia elétrica em emissões de $\mathrm{CO}_{2}$ foram utilizados os dados publicados no Balanço Energético Nacional (BEN, 2015) e para o diesel dados do relatório publicado pelo Painel Intergovernamental sobre Mudanças Climáticas (IPCC, 2006) em que:

- $1 \mathrm{MJ}$ energia elétrica $=0,038 \mathrm{kgCO}_{2}$

- $1 \mathrm{~L}$ diesel $=35,50 \mathrm{MJ}=2,63 \mathrm{kgCO} 2$

Na Tabela 1 são apresentados alguns valores de emissões de $\mathrm{CO}_{2}$ para o agregado graúdo (brita) encontrado na literatura.

Observa-se que os valores levantados apresentam uma considerável dispersão, com uma média de 2,95 kg$\mathrm{CO}_{2} / \mathrm{t}$ e coeficiente de variação de $50 \%$. O mais correto seria levantar as emissões de carbono para a realidade de
Goiânia, no entanto, não foi possível obter estes valores. Desta forma, os valores levantados servirão de parâmetro para comparar com o valor encontrado no processo de reciclagem dos resíduos para a produção da BGS.

Tabela 01: Emissões de $\mathrm{CO} 2$ para a produção de agregados graúdos naturais.

\begin{tabular}{|c|c|}
\hline \multicolumn{2}{|c|}{ Emissões agregados graúdos da literatura } \\
\hline Emissões $\left(\mathrm{kgCO}_{2} / \mathrm{t}\right)$ & Fontes \\
\hline 1,9 & Rossi (2013) \\
\hline 4,0 & Santoro e Kripka (2016) \\
\hline
\end{tabular}

Fonte: Elaborado pelos autores

\section{RESULTADOS E DISCUSSÃO}

Os resultados obtidos estão apresentados a seguir.

\subsection{Caracterização da empresa pesquisada}

Para o funcionamento da usina de reciclagem, a empresa conta com um total de oito funcionários contratados, distribuídos nas atividades administrativas e de produção.

De acordo com o responsável, a empresa apresenta um gasto mensal total médio de $\mathrm{R} \$ 60.000,00$, incluindo todos os gastos da produção e administrativos como aluguel, abastecimento de água, energia, contratação de mão de obra, combustíveis utilizados, entre outros. As atividades na usina acontecem de segunda a sexta-feira das 8:00 ás 18:00 h.

A empresa cobra uma taxa de $\mathrm{R} \$ 10,00 / \mathrm{m}^{3}$ para receber o entulho na usina. Durante a entrada dos resíduos na usina, são emitidas três vias do Controle de Resíduos (CTR), sendo a $1^{\circ}$ via entregue ao gerador, a $2^{\circ}$ via ao transportador e a $3^{\circ}$ via ao destinatário, que no caso é a própria empresa. No CTR constam as informações, assinaturas do gerador, transportador e destinatário, como também a caracterização, classificação e quantificação do resíduo recebido de acordo com o que é estabelecido nas resoluções do Conama.

Os resíduos chegam na empresa misturados com muitos materiais que não podem ser aproveitados no processo de reciclagem, como pedaços de madeira, metal, resíduos orgânicos, entre outros (Figura 2). Por isso é necessário que o

Figura 02 - Armazenamento temporário dos resíduos recebidos no pátio da usina

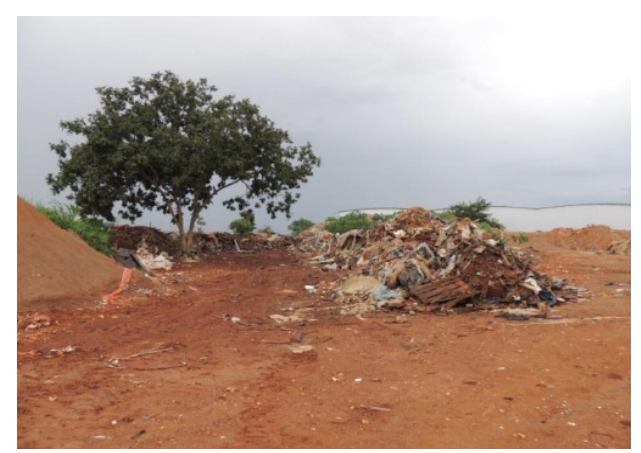

Fonte: Acervo dos autores (2015) 
resíduo bruto, como é chamado, passe por uma etapa de triagem, onde os resíduos Classe A são separados manualmente dos outros resíduos que não podem ser reaproveitados.

De acordo com as informações fornecidas pelo responsável pela empresa, aproximadamente $20 \%$ dos resíduos recebidos não podem ser reaproveitados no processo de reciclagem, que são separados no procedimento de triagem e encaminhados para o Aterro Sanitário Municipal de Goiânia, que cobra uma taxa de $\mathrm{R} \$$ 69,00/tonelada para a disposição final desses resíduos.

Após a triagem, os resíduos Classe A sãos transportados por uma pá carregadeira, até o alimentador, que recebe o resíduo e o encaminha por gravidade para a calha vibratória (Figura 3).

Figura 03-Transporte dos resíduos para oalimentador com a pá carregadeira
Fonte: Acervo dos autores (2015)

Com a vibração, as partículas finas e solo presentes no material passam pelos espaços produzidos pelos materiais de maior granulometria e se acumulam no fundo; em seguida, são removidos da calha por gravidade e encaminhados por uma esteira até o local de armazenamento temporário na Pilha (Figura 4).

Figura 04 - Esteira e armazenamento temporário de solo e partículas finas
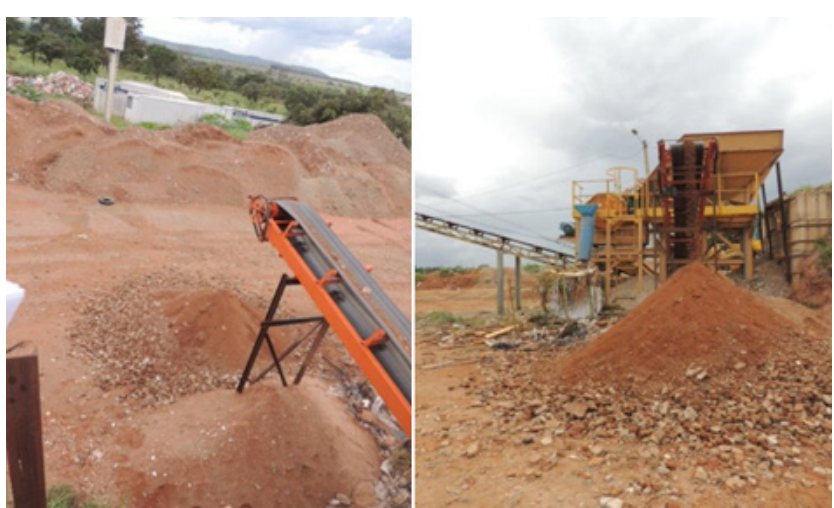

Fonte: Acervo dos autores (2015)
Os materiais que passam pela calha vibratória são encaminhados para o britador. O tipo de britador escolhido para o processo de reciclagem da empresa foi o britador de mandíbula, que possibilita a fragmentação dos materiais de grandes dimensões reduzindo-os para os processos seguintes sem a necessidade de uma fragmentação secundária.

Depois da britagem, o material é transportado por uma esteira até as peneiras vibratórias. Ao longo da esteira estão distribuídos dois ímãs, que realizam a separação de pequenos pedaços de metais que não são separados no processo de triagem (Figura 5).

Figura 05 - Esteira e dispositivo de ímã

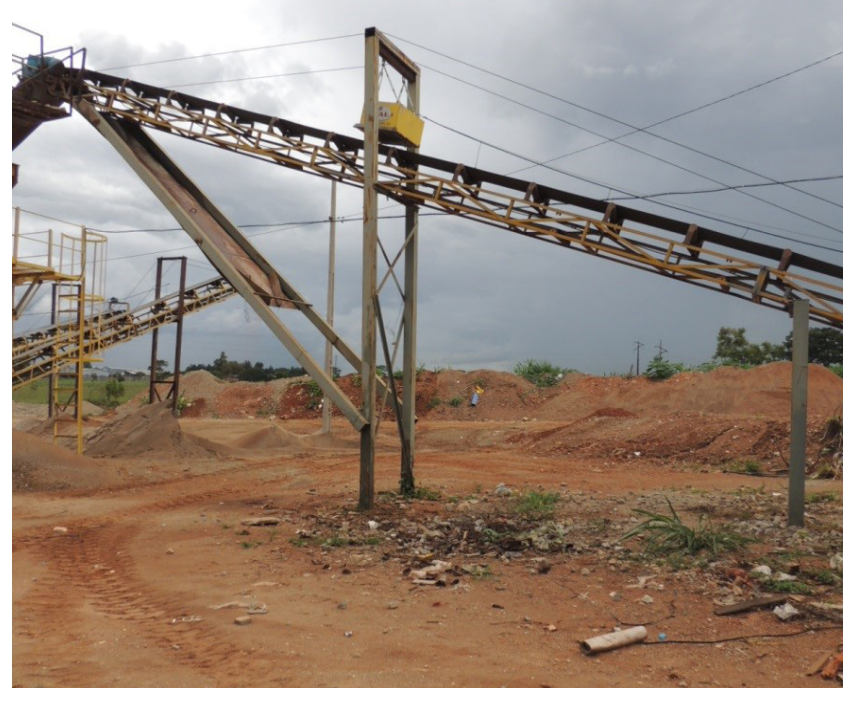

Fonte: Acervo dos autores (2015)

O peneiramento do material é realizado por três peneiras vibratórias posicionadas verticalmente, para promover a separação do material em quatro granulometrias, gerando os produtos finais do processo de reciclagem.

A primeira peneira, retém o Rachão, que é encaminhado por uma esteira até o local de armazenamento temporário em uma Pilha 1; a segunda peneira retém a Brita 1, que é encaminhado por uma esteira até o local de armazenamento temporário na Pilha 2; a terceira peneira retém o Pedrisco, que é encaminhado por uma esteira até o local de armazenamento temporário na Pilha 3; por fim, o material que passa pela terceira peneira é areia, que é encaminhado por uma esteira até o local de armazenamento temporário na Pilha 4 (Figura 6).

Além dos quatro produtos finais provenientes do processo de reciclagem, a empresa produz ainda um quinto produto, chamado de brita graduada simples (BGS), que é 
feita a partir da mistura dos outros materiais, em proporções exatas. Esse produto é bastante comercializado para obras de pavimentação (Figura 7).

Figura 06 - Peneiramento e pilhas de armazenamento temporário dos produtos finais

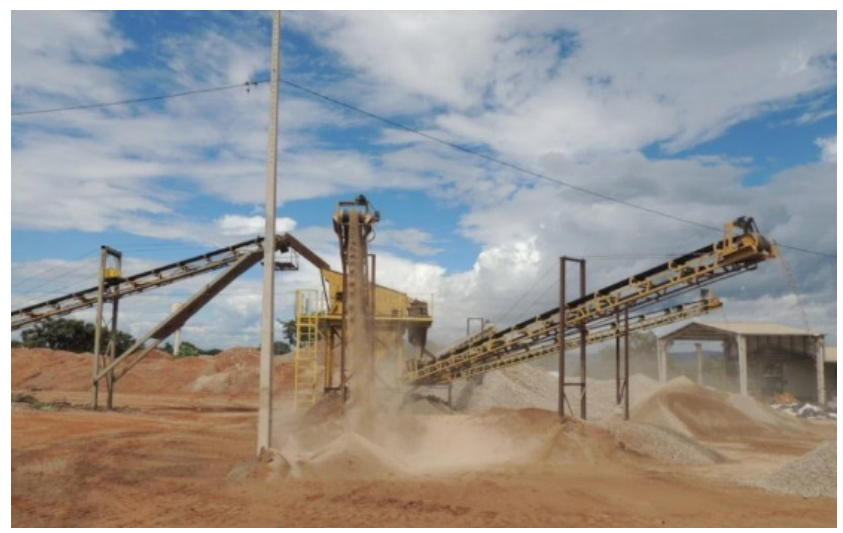

Fonte: Acervo dos autores (2015)

Figura 07 - Armazenamento temporário da brita graduada simples

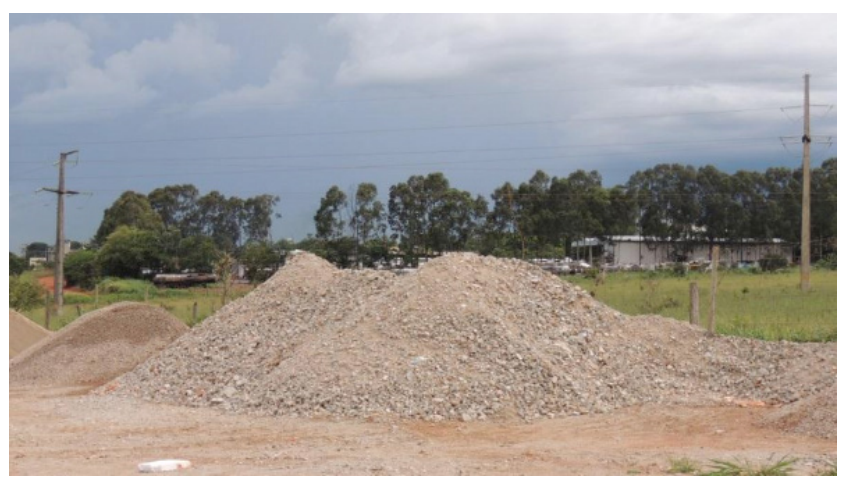

Fonte: Acervo dos autores (2015)

\subsection{Avaliação econômica}

A partir dos valores de venda pesquisados foram encontrados os custos apresentados na Figura 8.

Figura 08 - Comparação dos custos de aquisição

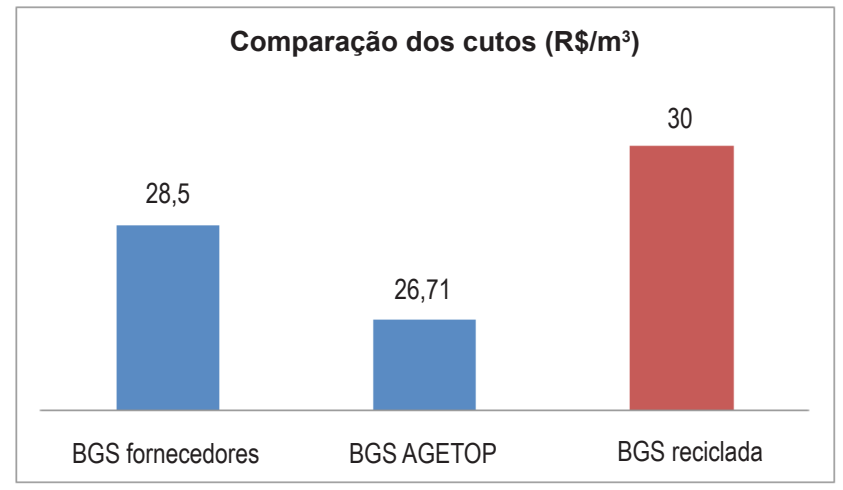

Fonte: Acervo dos autores (2015)

Percebe-se que o material reciclado comercializado pela empresa pesquisada apresentou valor de mercado superior ao do produto comercializado pelas principais fornecedoras no contexto do mercado econômico de Goiânia, com uma diferença entre 5 e 11\%.

Essa realidade pode ser explicada pelo fato da empresa estar trabalhando abaixo da sua capacidade de gerar lucros atualmente, entende-se que a partir do momento que a empresa receber uma quantidade de resíduos próxima a sua capacidade de produção, o preço final do seu produto poderá diminuir.

No entanto, é importante observar também que existe uma tendência de inversão dos preços apresentados a longo prazo, com a diminuição do preço do produto reciclado, e o aumento do preço do produto tradicional.

Este cenário de inversão é explicado pelo fato dos recursos naturais usados como matéria prima para a fabricação dos materiais de construção convencionais estão cada vez mais escassos, devido ao longo processo de exploração e degradação que sofreram ao longo dos anos.

Por outro lado, as alternativas de reaproveitamento e reciclagem dos RSCD tendem a ficarem mais acessíveis a partir de novas tecnologias e pesquisas, devendo ser incentivadas pela administração pública, com o objetivo de minimizar os impactos causados pela disposição inadequada desses resíduos e adequar-se as exigências de legislações ambientais recentes, incorporando assim, os custos ambientais ao preço final dos produtos.

\subsection{Avaliação das emissões de $\mathrm{CO}_{2}$}

Os valores de emissões de $\mathrm{CO}_{2}$ encontrados estão apresentados na Figura 9.

Figura 09 - Comparação dos custos de aquisição

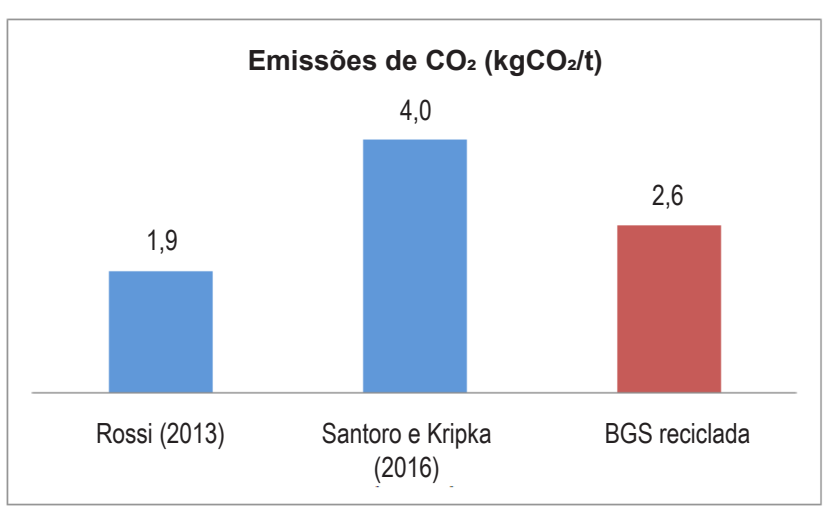

Fonte: Acervo dos autores (2015)

Observa-se que o valor de emissões de $\mathrm{CO}_{2}$ dos RSCD provenientes da empresa estudada foi inferior ao valor de Santoro e Kripka (2016) e superior ao valor apresentado por Rossi (2013), estando entre valor apresentado por Oliveira et al. (2013b), igual a 1,8 kgCO $/ \mathrm{t}$, e Berndt (2015), igual a 4,0 kgCO $/$ t, 
sendo que ambos avaliaram emissões para agregados reciclados. O valor de Berndt (2015) pode estar mais distante por se tratar de um estudo internacional, em que a tecnologia empregada e a matriz energética são diferentes da brasileira.

Desta forma, o processo de reciclagem realizado por esta empresa pode emitir menor quantidade de $\mathrm{CO}_{2}$ do que a produção de agregados naturais. Deve-se ressaltar que os números encontrados na literatura servem para uma primeira referência, porém isto não significa que a reciclagem é sempre mais vantajosa do ponto de vista de emissões, devendo ser analisado caso a caso. No entanto, é possível concluir que o processo de reciclagem, do ponto de vista de emissões não está distante do processo para a obtenção de agregados naturais, mostrando-se um processo viável.

Em estudos futuros sugere-se que sejam avaliadas as emissões dos agregados naturais da região goiania para comparação com os valores apresentado neste estudo, confirmando se os valores são próximos.

Pode ser avaliado o impacto das distancias de transporte para o município de Goiânia-GO, pois podem impactar de forma significativa, visto que o modal utilizado é o rodoviário com caminhões a diesel. Do ponto de vista da sustentabilidade para a destinação final de resíduos, além do tipo de procedimento adotado (aterramento, reciclagem, e etc.) deve-se atentar para à distância do local de geração de resíduos até o local de destinação final.

Deve-se ressaltar que mesmo se o processo de reciclagem for desvantajoso do ponto de vista de emissões de $\mathrm{CO}_{2}$, tem duas outras vantagens, que é a economia e preservação de recursos naturais e o aumento da vida útil dos locais de disposição final.

\section{CONCLUSÕES}

No presente trabalho foi realizada a avaliação econômica e ambiental (por meio da quantificação das emissões de $\mathrm{CO}_{2}$ ) do processo de reciclagem de RSCD classe $A$, para a realidade de Goiânia - GO.

Foi pesquisada e caracterizada uma empresa de reciclagem da região. Do ponto de vista econômico o agregado reciclado gerado, a brita graduada simples (BGS) para pavimentação, apresentou custo maior quando comparada ao valor de agregados naturais similares vendidos na região.

Conclui-se que mesmo a BGS tendo o custo mais elevado, a tendência é de uma inversão dos preços apresentados a médio e longo prazo, tendo em vista o aumento do preço do produto tradicional, devido à diminuição de disponibilidade de produtos naturais no futuro.

Do ponto de vista das emissões de $\mathrm{CO}_{2}$, a BGS gerada na empresa apresentou valor intermediário entre os valores de emissões dos agregados naturais pesquisados na literatura, mostrando se viável.

Para futuras pesquisas sugere-se avaliar as emissões de $\mathrm{CO}_{2}$ dos agregados naturais da região, incorporar os custos associados à destinação final e transporte dos resíduos, que não foram contabilizados no presente trabalho como também a avaliação de outros impactos ambientais relacionados à reciclagem de RSCD classe $A$.

\section{REFERÊNCIAS}

[1] SINDICATO DA INDÚSTRIA DA CONSTRUÇÃO CIVIL DO CEARÁ - SINDUSCON-CE. Manual sobre resíduos sólidos da Construção Civil. Fortaleza, 2011.

[2] HENDRIKS, C. F.; NIJKERK, A. A.; VAN KOPPEN, A. E. O Ciclo da Construção. 1ed. Brasília: Editora da Universidade de Brasília, 2007. 250p.

[3] ADDIS, B. Reúso de materiais e elementos de construção. 1ed. São Paulo: Oficina de Textos, 2010. 368p.

[4] TORGAL, P. F.; TAM, V. W. Y.; LABRINCHA, J.A.; DING, Y.; BRITO, J. Handbook of recycled concrete and demolition waste. 1ed. Cambridge: Woodhead Publishing Limited, 2013. 663 p.

[5] JOHN, V. M. Reciclagem de resíduos na construção civil: contribuição à metodologia de pesquisa e desenvolvimento. Tese de livre docência. Escola Politécnica, Universidade de São Paulo, São Paulo, 2000.

[6] CARNEIRO, A. P.; BRUM, I. A. S.; CASSA, J. C. S. (ORG). Reciclagem de resíduo para a produção de materiais de construção. Projeto resíduo bom. Salvador: EDUFBA, Caixa Econômica Federal. 2001.

[7] MIRANDA, L. F. R.; ANGULO, S. C.; CARELI, E. D. A reciclagem de resíduos de construção e demolição no Brasil: 1986-2008. Ambiente Construído, Porto Alegre, v. 9, n. 1, p. 57-71, jan./mar. 2009.

[8] SILVA, R. B da; ANGULO, S. C.; PILEGGI, R. G.; SILVA, C. O. Concretos secos produzidos com agregados reciclados de RCD separados por densidade. Ambiente Construído, Porto Alegre,v. 15, n. 4, p. 335-349, out./dez. 2015.

[9] BRASIL. CONSELHO NACIONAL DO MEIO AMBIENTE - CONAMA. Resolução n 307, de 5 de julho de 2002. 
[10] . CONSELHONACIONALDOMEIO AMBIENTE - CONAMA. Resolução n 348, de 16 de agosto de 2004.

[11] CONSELHO NACIONAL DO MEIO AMBIENTE CONAMA. Resolução Conama n 431, de 24 de maio de 2011.

[12] FERREIRA, R. C.; SILVA, W. M.; SOUZA, L. O.; SILVA, A. M. Gerenciamento de resíduos da construção civil e demolição e sua utilização como base, sub-base e mistura betuminosa em pavimento urbano em Goiânia GO. Revista Brasileira de Ciências Ambientais, n 15, 2010.

[13] CALDAS, L. R.; MENDES, M. M.; NASCIMENTO, M. L. M.; FONTELES, D. A. Avaliação do Gerenciamento de Resíduos da Construção Civil em Canteiros de Obra. In: CONGRESSO BRASILEIRO DO CONCRETO, 57., 2015. Anais... Bonito, MS, 2015.

[14] OLIVEIRA, W. N.; ROCHA, V. P.; FERREIRA, O. M. Mapeamento dos pontos de disposição de resíduos da construção civil e demolição em Goiânia. In: XVI SIMPÓSIO BRASILEIRO DE SENSORIAMENTO REMOTO, 15. 2013. Anais... Foz do Iguaçu, 2013 a.

[15] CONSELHONACIONALDO MEIO AMBIENTE - CONAMA. Resolução n 448, de 19 de janeiro de 2012.

[16] ÂNGULO, S. C.; KAHN, H.; JOHN, V. M.; ULSEN, C. Metodologia de caracterização de resíduos da construção e demolição. Seminário de desenvolvimento sustentável e a reciclagem na construção civil. IBRACON. São Paulo, 2003.

[17] MOTTA, R. S. Estudo laboratorial de agregado reciclado de resíduo sólido da construção civil para aplicação em pavimentação de baixo volume de tráfego. Dissertação de mestrado, Escola Politécnica da Universidade de São Paulo, 2005.

[18] LUZ, A. B.; SAMPAIO, S. L. M. Tratamento de minérios. $4^{\circ}$ Edição. CETEM-MCT, Rio de Janeiro, 2004.

[19] JOHN, V. M. Aproveitamento de resíduos sólidos como materiais de construção. In: CARNEIRO, A. P.; BRUM, I. A. S.; CASSA, J. C. S. (ORG). Reciclagem de resíduo para a produção de materiais de construção. Projeto resíduo bom. Salvador: EDUFBA, Caixa Econômica Federal. 2001.

[20] TURK, J.; COTIC, Z.; MLADENOVIC, A.; ŠAJNA, $A$. Environmental evaluation of green concretes versus conventional concrete by means of LCA. Waste Management. v. 45. p. 2231 - 2242. 2015.

[21] JIMÉNEZ, C.; BARRA, M.; JOSA, A.; SUSANNA, V. LCA of recycled and conventional concretes designed using the equivalent mortar volume and classic methods. Construction and Building Materials journal. v. 84. p. 245-252. 2015.

[22] SERRES, N.; BRAYMAND, S.; FEUGEAS, F. Environmental evaluation of concrete made from recycled concrete aggregate implementing life cycle assessment. Journal of Building Engineering. v. 5. p. $24-33.2016$.

[23] SEIFFERT, M. E. B. Gestão Ambiental Instrumentos, esferas de ação e educação ambiental. 2 ed. São Paulo: Editora Atlas, 2011.

[24] JOHN, V. M. Materiais de Construção e o Meio Ambiente. In: ISAIA, G. Materiais de Construção Civil e Princípios de Ciência e Engenharia de Materiais. São Paulo: IBRACON, 2010. p. 97-121.

[25] AGÊNCIA GOIANA DE TRANSPORTES E OBRAS - AGETOP. Custo referencial de materiais - Tabela de Terraplanagem, pavimentação e obras de arte especiais. Dezembro de 2014.

[26] BALANÇO ENERGÉTICO NACIONAL (BEN) 2015: Relatório Síntese ano base 2014. Brasília-DF, 2015.

[27] IPCC. 2006. Guidelines for National Greenhouse Gas Inventories, v. 2- Energy. Disponível em: <http:// www.ipcc-nggip.iges.or.jp> Acesso em 20 ago. 2015.

[28] ROSSI, E. Avaliação do ciclo de vida da brita para a construção civil: estudo de caso. Dissertação (Mestrado), Universidade Federal de São Carlos, São Carlos, 2013.

[29] SANTORO, J. F.; KRIPKA, M. Determinação das emissões de dióxido de carbono das matérias primas do concreto produzido na região norte do Rio Grande do Sul. Ambiente Construído, Porto Alegre, v. 16, n. 2, p. 35-49, abr./jun. 2016.

[30] OLIVEIRA, L. S. et al. Emissões de $\mathrm{CO}_{2}$ dos agregados reciclados de resíduos de construção e demolição (RCD): dois estudos de caso. 3., Anais... Encontro 
Nacional Sobre Reaproveitamento de Resíduos na Construção Civil - ENARC, 2013b. p. 15.

[31] BERNDT, M. L. Influence of concrete mix design on $\mathrm{CO} 2$ emissions for large wind turbine foundations.

Renewable Energy. v. 83. p. 608-614. 2015. 